\title{
Fingerprint Analysis and Simultaneous Determination of Phenolic Compounds in Extracts of Curculiginis Rhizoma by HPLC-Diode Array Detector
}

\author{
Qingya Bian, ${ }^{a}$ Hui Yang, ${ }^{b}$ Chi-on Chan, ${ }^{b}$ Dengping Jin, ${ }^{b}$ Daniel Kam-Wah Mok, ${ }^{b}$ and \\ Sibao Chen*,b,c \\ ${ }^{a}$ Yancheng Institute of Health Science; Yancheng 224005, China: ${ }^{b}$ State Key Laboratory Incubation Base of \\ Chinese Medicine and Molecular Pharmacology, Department of Applied Biology and Chemical Technology, \\ The Hong Kong Polytechnic University; Shenzhen 518057, P. R. China: and ${ }^{c}$ Institute of Medicinal Plant Development, \\ Chinese Academy of Medical Sciences and Peking Union Medical College; Beijing 100193, P. R. China. \\ Received December 12, 2012; accepted May 23, 2013
}

Curculiginis Rhizoma (Curculigo orchioides GAERTN.) is a well-known Chinese herbal medicine, as well as an important Rasayana drug in India. Current criteria of quality control on this herb are to quantitatively analyze single compound curculigoside, which fail to comprehensively evaluate quality of this herb. In this paper, a simple and reliable HPLC coupled with diode array detector (DAD) method was developed to evaluate the quality of Curculiginis Rhizoma through establishing chromatographic fingerprint and simultaneously quantitating four phenolic compounds, orcinol glucoside, orcinol, 2,6-dimethoxybenzoic acid and curculigoside. The fingerprint displayed eleven common peaks, and the similarity index of different samples was in a range of $0.890-0.977$. Validation of the method was acceptable, with $96.03-102.82 \%$ accuracy in recovery test and inter and intra-day precisions were less than $2 \%$. This developed method by having a combination of chromatographic fingerprint and quantitation analysis could be applied to the quality control of Curculiginis Rhizoma. side

Key words Curculiginis Rhizoma; phenolic compound; HPLC fingerprint; Curculigo orchioides; curculigo-

Curculiginis Rhizoma (CR), the dry rhizome of Curculigo orchioides GAERTN. (Amaryllidaceae) is a well-known Chinese herbal medicine, ${ }^{1)}$ as well as one of the reputed drug mentioned in the ancient India medicine system used as an analgesic, antiinflammatory, spermatogenic, aphrodisiac, immunostimulant, hepatoprotective, and antiasthamatic, etc. ${ }^{2}$

Due to remarkable pharmacological activities including hepatoprotective, ${ }^{3)}$ immunomodulatory and antioxidant, ${ }^{4,5}$ estrogenic and antiosteoporotic, ${ }^{6,7)}$ antidiabetic, ${ }^{8)}$ and antiasthmatic activities, ${ }^{9)}$ the utilization of CR is currently increasing, which raises an urgent need for compositional information for selecting raw materials of $\mathrm{CR}$ with best quality for drug industries. Chemical studies revealed a variety of constituents, including phenols and its glycosides, ${ }^{10,11)}$ chlorophenolic glycosides, ${ }^{12)}$ and cycloartane saponins ${ }^{13,14)}$ are present in this herb. Pharmacological investigation demonstrated that curculigoside, the dominant phenolic compound, possessing ameliorative effects on learning and memory, ${ }^{15)}$ neuroprotective ${ }^{16)}$ and osteoblast-protective activities ${ }^{17)}$ was considered as major active compound of CR. Therefore, by far quantitiation on cur- culigoside by HPLC method has been used as the unique criterion in quality control of CR and its products. ${ }^{1,18)}$ However, it is well known that the therapeutic effect of herbal medicine is based on the synergic effect of its mass bioactive compounds, and further biological studies revealed a number of phenolic compounds in this herb were responsible for its antiosteoporotic activity. ${ }^{6}$ Current methods only dealt with the quantitation of curculigoside and fail to present any information of the other components. In recent years, fingerprinting has been internationally accepted as an efficient technique for the quality control of complex analytes, especially for Chinese herbal medicine. ${ }^{19,20)}$ Thus, in the present paper, a HPLC-diode array detector (DAD) method was developed and applied for the quality evaluation of $\mathrm{CR}$ in establishing chromatographic fingerprinting profile and simultaneous determination of four phenolic compounds (markers) including orcinol glucoside (1), orcinol (2), 2,6-dimethoxybenzoic acid (3) and curculigoside (4) (Fig. 1).<smiles>Cc1cc(O)cc(OC(O)C(O)C(O)C(O)O)c1</smiles>

orcinol glucoside (1)<smiles>Cc1cc(O)cc(O)c1</smiles>

orcinol (2)<smiles>COc1cccc(OC)c1C(=O)O</smiles>

2, 6-dimethoxybenzoic acid (3)<smiles>COc1cccc(OC)c1C(=O)OCc1cc(O)ccc1OC1OC2COC(O2)C1O</smiles>

curculigoside (4)

Fig. 1. Chemical Structures of Compounds 1-4 
Table 1. A Summary of the Tested Samples

\begin{tabular}{|c|c|c|c|}
\hline Sample & Sample code & Sample source & Date of collection \\
\hline 1 & XM-01 & $\begin{array}{l}\text { Jingxi, Guangxi prov- } \\
\text { ince, China }\end{array}$ & $2008-12-20$ \\
\hline 2 & XM-02 & $\begin{array}{l}\text { Yulin, Guangxi prov- } \\
\text { ince, China }\end{array}$ & $2009-02-20$ \\
\hline 3 & XM-03 & $\begin{array}{l}\text { Qianxi, Guizhou prov- } \\
\text { ince, China }\end{array}$ & $2009-05-10$ \\
\hline 4 & XM-04 & $\begin{array}{l}\text { Fengcheng, Jiangxi } \\
\text { province, China }\end{array}$ & $2009-02-21$ \\
\hline 5 & XM-05 & $\begin{array}{l}\text { Tiandong, Guangxi } \\
\text { province, China }\end{array}$ & $2008-12-23$ \\
\hline 6 & XM-06 & $\begin{array}{l}\text { Kunming, Yunnan prov- } \\
\text { ince, China }\end{array}$ & $2009-12-07$ \\
\hline 7 & XM-07 & $\begin{array}{l}\text { Jiajiang, Sichuan prov- } \\
\text { ince, China }\end{array}$ & $2009-04-03$ \\
\hline 8 & XM-08 & $\begin{array}{l}\text { Danling, Sichuan prov- } \\
\text { ince, China }\end{array}$ & $2009-04-03$ \\
\hline 9 & XM-09 & $\begin{array}{l}\text { Yibing, Sichuan prov- } \\
\text { ince, China }\end{array}$ & 2009-09-06 \\
\hline 10 & XM-10 & $\begin{array}{l}\text { Qujing, Yunnan prov- } \\
\text { ince, China }\end{array}$ & $2009-11-06$ \\
\hline
\end{tabular}

\section{Experimental}

Chemicals, Reagents and Materials Rhizome samples of Curculigo orchioides were collected from Sichuan, Yunnan, Gunagxi, Guizhou provinces in P.R. China, respectively (Table 1). The plant materials were authenticated by one of the authors Dr. Sibao Chen according to their morphological characteristics. The voucher specimens are deposited in the State Key Laboratory Incubation Base of Chinese medicine and Molecular Pharmacology at Hong Kong Polytechnic University (Shenzhen, China).

D-101 macroporous resin was purchased from Shanghai Hualing Resin Co., Ltd. (Shanghai, China). Silica gel (200-300 mesh) was from Qingdao Marine Chemical (Qingdao, China) and Sephadex LH-20 $(25-100 \mu \mathrm{m})$ from Pharmacia Fine Chemical Co., Ltd. (Uppsala, Sweden). Acetonitrile, trifluoroacetic acid (HPLC grade) was purchased from Fisher (Fisher Scientific, U.S.A.) while methanol, ethanol (analytical grade) from Guangzhou Jinhuada (Guangzhou, China). Deionized water was obtained from a Millipore Milli-Q system (Bedford, MA, U.S.A.). Cellulose acetate membrane filters $(0.45 \mu \mathrm{m})$ were purchased from Dalian Elite Analytical Instruments (Dalian, China). Standard compounds $\mathbf{1} \mathbf{- 3}$ were isolated from $\mathrm{CR}$ and identified by comparing their spectral data with those reported in the literature. Their purities were determined by HPLC-DAD with relative area percentage and were not less than $98.0 \%$. Curculigoside was purchased from the Chinese National Institute for Control of Pharmaceutical and Biological Products (Beijing, China).

Apparatus and Chromatographic Conditions ${ }^{1} \mathrm{H}-$ and ${ }^{13} \mathrm{C}$-NMR spectra were detected on Bruker-Avance- 400 equipment (Bruker BioSpin, Billerica, MA, U.S.A.). Chromatographic analysis was carried out on Alltima $\mathrm{C}_{18}$-column $(4.6 \times 250 \mathrm{~mm}, 5 \mu \mathrm{m})$ at $30^{\circ} \mathrm{C}$ using an Agilent 1100 liquid chromatography system, equipped with the G1311A Quatpump solvent delivery system, UV-VIS photodiode array detector G1315B and degasser G1322A. The detection wavelength was set at $220 \mathrm{~nm}$. The mobile phase was composed of acetonitrile containing $0.02 \%(\mathrm{v} / \mathrm{v})$ trifluoroacetic acid (A) and $0.5 \%$ aqueous trifluoroacetic acid $(\mathrm{v} / \mathrm{v})(\mathrm{B})$ using the stepwise gradients
Table 2. The Stepwise Gradient of the Mobile Phase

\begin{tabular}{ccc}
\hline \hline $\begin{array}{r}\text { Time } \\
(\mathrm{min})\end{array}$ & $\begin{array}{c}\text { A }(0.02 \% \text { Trifluoroacetic } \\
\text { acid in acetonitrile })\end{array}$ & $\begin{array}{c}\text { B }(0.05 \% \text { Trifluoroacetic } \\
\text { acid })\end{array}$ \\
\hline 0 & 7 & 93 \\
13 & 15 & 85 \\
20 & 20 & 80 \\
30 & 30 & 70 \\
35 & 30 & 70 \\
\hline
\end{tabular}

elution (Table 2): linear gradient $7-15 \% \mathrm{~A}$ at $0-13 \mathrm{~min}$, linear gradient $15-20 \%$ A at $13-20 \mathrm{~min}$, linear gradient $20-30 \% \mathrm{~A}$ at $20-30 \mathrm{~min}$, isocratic $30 \% \mathrm{~A}$ at $30-35 \mathrm{~min}$. The flow rate was $1.0 \mathrm{~mL} / \mathrm{min}$ and aliquots of $10 \mu \mathrm{L}$ were injected into the HPLC.

Isolation and Identification of Orcinol Glucoside, Orcinol, and 2,6-Dimethoxybenzoic Acid in CR Air dried CR sample $(10 \mathrm{~kg})$ was pulverised and refluxed with $90 \%$ ethanol for 3 times ( $2 \mathrm{~h}$ per time) at room temperature. The extracts were combined, filtered and dried using a rotary evaporator under reduced pressure. The residue $(810 \mathrm{~g})$ was suspended in water and partitioned successively with petrol ether $\left(60-80^{\circ} \mathrm{C}\right)$, ethyl acetate and 1-butanol. The ethyl acetate fraction $(180 \mathrm{~g})$ was subjected to silica gel column chromatography eluted with gradients of dichloromethane-acetone $(100: 1$, $50: 1,20: 1)$ to obtain 3 subfractions $\left(B_{1}-B_{3}\right)$; fraction $B_{2}$ was purified on a Sephadex LH-20 column with methanol-water $(60: 40, \mathrm{v} / \mathrm{v})$ as mobile phase to yield compound $2(20 \mathrm{mg})$; fraction $\mathrm{B}_{3}$ was subjected further silica gel chromatography to afford compound $3(30 \mathrm{mg})$. The butanol extract $(400 \mathrm{~g})$ was separated chromatographically on a D-101 macroporous resin column eluted with water and $90 \%$ ethanol, respectively. The $90 \%$ ethanol fraction (50 g dry mass) was further separated by silica gel column chromatography eluted with gradients of dichloromethane-methanol $(10: 1,7: 1,5: 1)$ to afford three subfractions $\left(\mathrm{C}_{1}-\mathrm{C}_{3}\right)$; fraction $\mathrm{C}_{2}$ was chromatographed on silica column eluted with dichloromethane-methanol $(9: 1)$ as solvent system to yield compound $\mathbf{1}(500 \mathrm{mg})$. The structures of these compounds were determined by their spectroscopic data. ${ }^{21-23)}$

Orcinol Glucoside (1): White powder, ${ }^{1} \mathrm{H}-\mathrm{NMR}\left(\mathrm{C}_{5} \mathrm{D}_{5} \mathrm{~N}\right) \delta$ : $2.18\left(3 \mathrm{H}, \mathrm{s}, \mathrm{CH}_{3}\right), 5.65\left(1 \mathrm{H}, \mathrm{d}, J=7.2 \mathrm{~Hz}, \mathrm{H}-1^{\prime}\right), 6.75(1 \mathrm{H}, \mathrm{s}$, H-6), $6.8(1 \mathrm{H}, \mathrm{s}, \mathrm{H}-4), 7.19(1 \mathrm{H}, \mathrm{s}, \mathrm{H}-2), 4.20-4.45(6 \mathrm{H}, \mathrm{m}$, $\mathrm{H}$-glu), $11.54\left(1 \mathrm{H}\right.$, brs, 3-OH); ${ }^{13} \mathrm{C}-\mathrm{NMR}\left(\mathrm{C}_{5} \mathrm{D}_{5} \mathrm{~N}\right) \delta: 160.1$ (C-1), 109.0 (C-2), 160.1 (C-3), 111.2 (C-4, C-6), 140.5 (C-5), $21.7\left(-\mathrm{CH}_{3}\right), 102.4\left(\mathrm{C}-1^{\prime}\right), 78.7\left(\mathrm{C}-2^{\prime}\right), 75.1\left(\mathrm{C}-3^{\prime}\right), 71.3\left(\mathrm{C}-4^{\prime}\right)$, $78.6\left(\mathrm{C}-5^{\prime}\right), 62.4\left(\mathrm{C}-6^{\prime}\right)$.

Orcinol (2): Colorless needles, ${ }^{1} \mathrm{H}-\mathrm{NMR}\left(\mathrm{CD}_{3} \mathrm{COCD}_{3}-d_{6}\right) \delta$ : $3.09\left(3 \mathrm{H}, \mathrm{s}, \mathrm{CH}_{3}\right), 6.05(2 \mathrm{H}, \mathrm{s}, \mathrm{H}-2, \mathrm{H}-6), 8.03(1 \mathrm{H}, \mathrm{s}, \mathrm{H}-4)$; ${ }^{13} \mathrm{C}-\mathrm{NMR}\left(\mathrm{CD}_{3} \mathrm{COCD}_{3}-d_{6}\right) \delta: 140.5(\mathrm{C}-1), 108.3(\mathrm{C}-2, \mathrm{C}-6)$, 159.3 (C-3,C-5), 100.6 (C-4), $21.5\left(\mathrm{CH}_{3}\right)$.

2,6-Dimethoxybenzoic acid (3): Colorless needles, ${ }^{1} \mathrm{H}-\mathrm{NMR}$ $\left(\mathrm{C}_{5} \mathrm{D}_{5} \mathrm{~N}\right) \delta: 3.69\left(6 \mathrm{H}, \mathrm{s}, \mathrm{OCH}_{3}\right), 6.66(2 \mathrm{H}, \mathrm{d}, J=8.4 \mathrm{~Hz}, \mathrm{H}-3$, $\mathrm{H}-5), 7.30(1 \mathrm{H}, \mathrm{d}, J=8.4 \mathrm{~Hz}, \mathrm{H}-4), 12.88(1 \mathrm{H}, \mathrm{brs}, \mathrm{COOH})$, ${ }^{13} \mathrm{C}-\mathrm{NMR}\left(\mathrm{C}_{5} \mathrm{D}_{5} \mathrm{~N}\right) \quad \delta: 116.9(\mathrm{C}-1), 157.6(\mathrm{C}-2), 104.8(\mathrm{C}-3)$, 130.8 (C-4), 104.8 (C-5), 157.9 (C-6), $56.2 \quad\left(\mathrm{OCH}_{3}\right), 168.7$ $(\mathrm{COOH})$.

Preparation of Standard Solution Standards were weighed accurately and dissolved in $5 \mathrm{~mL}$ of methanol to prepare the stock solutions of compounds $\mathbf{1}(5 \mathrm{mg} / \mathrm{mL}), \mathbf{2}(0.4 \mathrm{mg} /$ $\mathrm{mL}), 3(0.4 \mathrm{mg} / \mathrm{mL}), 4(5 \mathrm{mg} / \mathrm{mL})$, respectively. Mixed-stock standard solution at the concentrations of 500.0, 40.0, 40.0, 


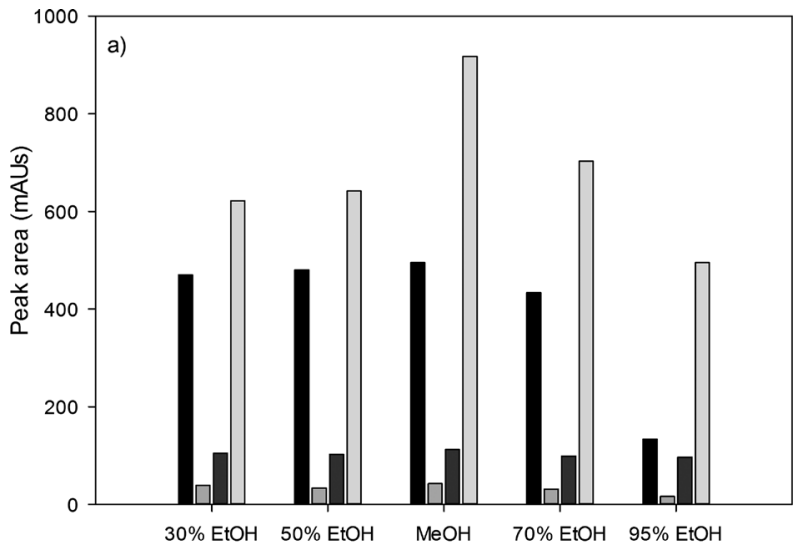

Extraction solvent

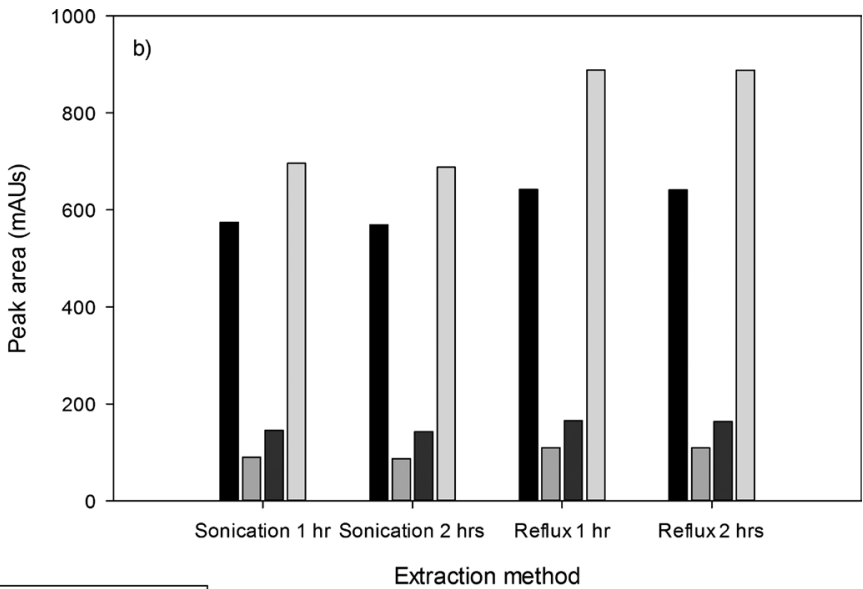

Extraction method

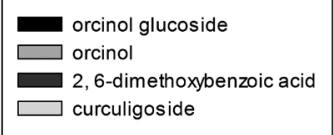

Fig. 2. Results Obtained in the Optimization of the Extraction Conditions

a) Extraction efficiency of different solvents. b) Extraction efficiency of different extraction methods.

and $500.0 \mu \mathrm{g} / \mathrm{mL}$ for standards $\mathbf{1}-\mathbf{4}$ was made by pipetting $1.0 \mathrm{~mL}$ of each stock standard solution into a $10.0 \mathrm{~mL}$ volumetric flask, and diluting to volume with methanol. Mixed-stock standard solution was filtered through a $0.45-\mu \mathrm{m}$ cellulose acetate membrane filter before HPLC analysis.

Preparation of Sample Solutions Two grams of sample was weighed accurately and refluxed with $45 \mathrm{~mL}$ methanol for $60 \mathrm{~min}$ in into a $100-\mathrm{mL}$ round bottomed flask. Then, the mixture was transferred to centrifugal tube and centrifuged (3000 rpm) for $15 \mathrm{~min}$. The residue was washed with $5 \mathrm{~mL}$ of methanol and transferred to centrifugal tube and centrifuged (3000 rpm) for $15 \mathrm{~min}$. All supernatant were combined and transferred into a $50 \mathrm{~mL}$ volumetric flask. The solution was finally marked up by methanol and was filtrated through a 0.45 $\mu \mathrm{m}$ cellulose acetate membrane filter before HPLC analysis.

Data Analysis of Fingerprint Similarity analysis was performed by professional software named Similarity Evaluation System for Chromatographic Fingerprint of Traditional Chinese Medicine (Version 2004A), which was recommended by State Food and Drug Administration of China (SFDA). The software was to employ the correlative coefficient in evaluating the similarities of different chromatograms.

Validation of HPLC-DAD Quantitative Methods Standard solutions of the four analytes were prepared and diluted to appropriate concentrations. A range of six concentrations of the four analytes were analyzed by three replicate injections to evaluate linearity of this method. The limit of detection (LOD) and quantitation (LOQ) under the chromatographic analysis at signal-to-noise ratio $(S / N)$ of 3 and 10 , respectively, were determined for each analytes. The intra- and inter-day precision was determined by analyzing the known concentrations of four analytes in six replicates during a single day and duplicated on 3 successive days, respectively in room temperature. The repeatability was evaluated by five duplicate determinations of four analytes in the same sample in room temperature. The relative standard deviation (RSD) was taken as a measure of precision and repeatability. Meanwhile, recovery tests were performed to examine the accuracy of the analytical method. Accurate amounts of individual standards were added to approximate $2.0 \mathrm{~g}$ of CR sample, and which was then analyzed as described above. Triplicate experiments were performed to determine the percentage of recoveries.

\section{Results and Discussion}

Optimization of Extraction In order to obtain the optimal extraction conditions, the influences of the solvents, extraction methods and duration on the extraction efficiencies were investigated. Methanol, and volumetrically diluted ethanol $(95 \%, 70 \%, 50 \%, 30 \%, \mathrm{v} / \mathrm{v})$ were used for preliminary extraction and, as shown in Fig. 2a, methanol was shown to be the most effective by comparing the peak areas of four markers in HPLC chromatograms. Successive extractions were also carried out independently and the results indicated that saturation of phenolic compounds were found by using $70 \%$ and $95 \%$ ethanol as solvent in the first extraction cycle. Finally, different extraction methods were examined by comparison of the extraction yield of the four markers in CR with methanol. The results shown in Fig. $2 \mathrm{~b}$ revealed that heat reflux for $2 \mathrm{~h}$ could obtain best yields for all markers.

Optimization of the Chromatographic Conditions To achieve a better resolution in an HPLC analysis, an Alltima $\mathrm{C}_{18}$ ODS column was used for the analysis of 4 markers in CR after compared the results by using others columns with different brands. DAD was applied to select the optimized wavelength of constituents in the HPLC analysis. In a full-scan chromatogram depicted in Fig. 3a, not only lots of peaks can be detected at $220 \mathrm{~nm}$ (Fig. 3b), but also 4 markers also shown good absorptivity than at other wavelength by comparing with $254 \mathrm{~nm}$ (Fig. 3c) and $280 \mathrm{~nm}$ (Fig. 3d). However, more interference was also observed in those wavelengths, which is smaller than $220 \mathrm{~nm}$. In order to reflect as much as informative chemical characteristics of $\mathrm{CR}$, the most appropriate wavelength was set as $220 \mathrm{~nm}$.

Two mobile phase systems including acetonitrile-water or methanol-water were compared to provide best separation conditions and the optimum one was found to be a gradient prepared from acetonitrile-water system. In addition, different types of acid modifier such as acetic acid, formic acid, 
a)
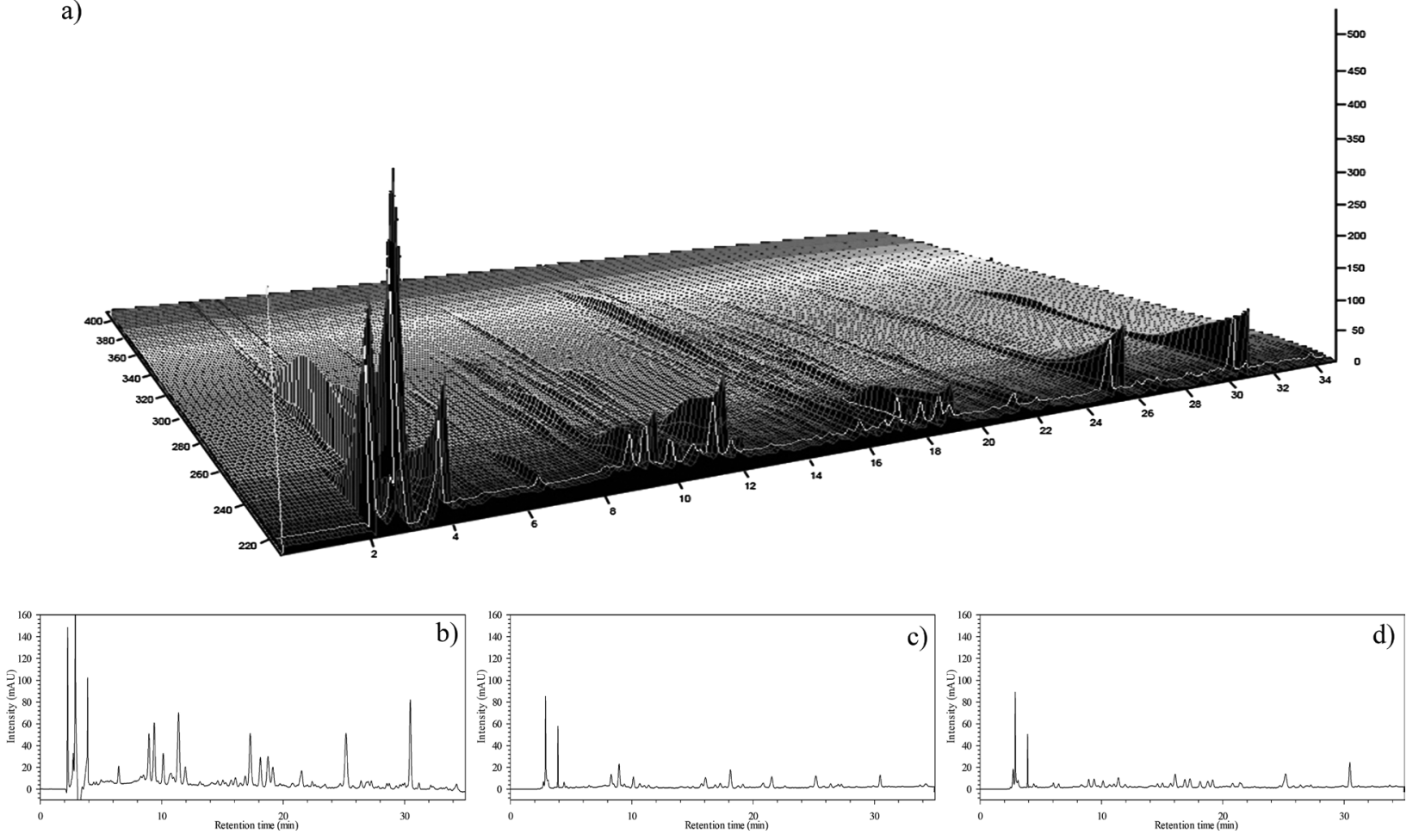

Fig. 3. HPLC Chromatogram of CR Extract Visualized by a) 3D, b) $220 \mathrm{~nm}$, c) $254 \mathrm{~nm}$, and d) $280 \mathrm{~nm}$
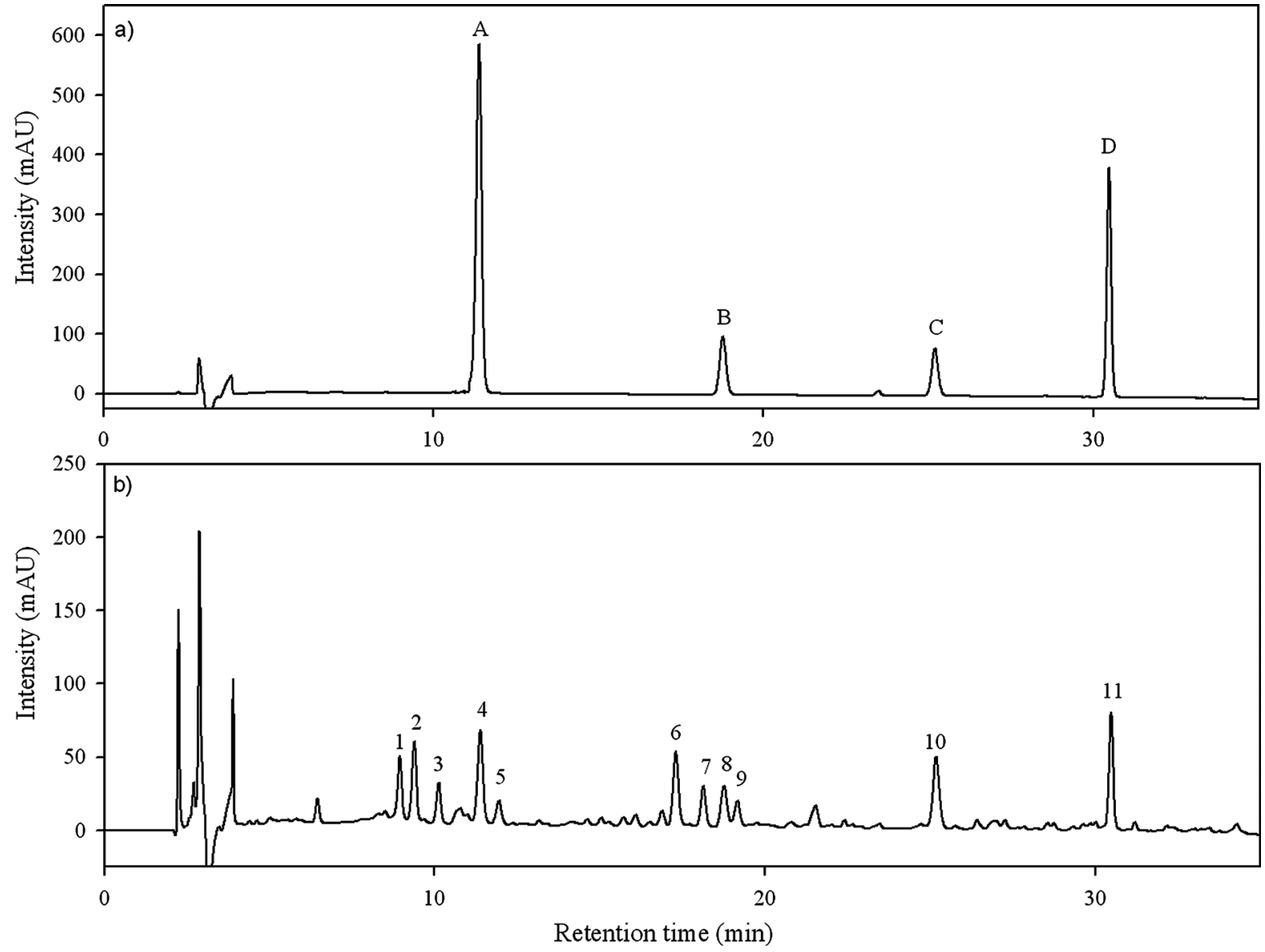

Fig. 4. HPLC Chromatograms, Recorded at 220nm, of a) of a Mixture of Standards (A: Orcinol Glucoside; B: Orcinol; C: 2,6-Dimethoxybenzoic Acid; D: Curculigoside) and b) of a Typical Curculiginis Rhizoma Sample

Number Peak 4: orcinol glucoside; Peak 7: orcinol; Peak 10: 2,6-dimethoxybenzoic acid, and Peak 11: curculigoside. 


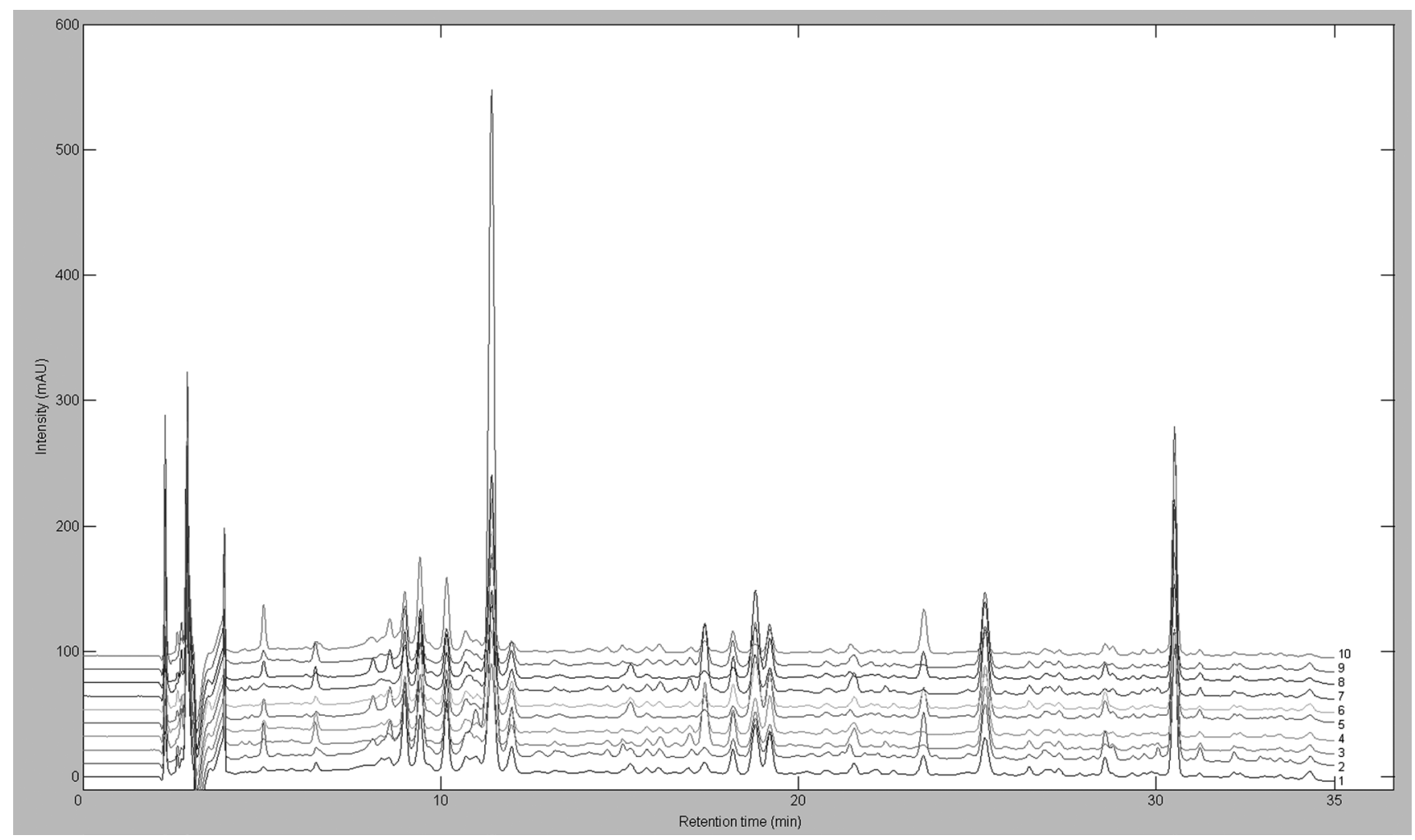

Fig. 5. HPLC Fingerprint of 10 Batches of Samples

phosphoric acid and trifluoroacetic acid were tried to add into mobile phase to eliminate the peak tailing of the target compounds, respectively. As a result, trifluoroacetic acid (TFA) was selected as modifier. The final chromatographic conditions were obtained with a gradient elution system consists of acetonitrile containing $0.02 \%(\mathrm{v} / \mathrm{v})$ TFA and $0.5 \%(\mathrm{v} / \mathrm{v})$ aqueous TFA and satisfactory separation with 4 markers were obtained within $35 \mathrm{~min}$. Since the resolution value between markers and adjacent peaks are larger than 1.5, the chromatographic system will be further used as quantitation in the assay section.

HPLC-UV Fingerprint Analysis To perform fingerprinting analysis, the chromatograms of different samples have to be standardized. The process of standardization included the selection of "common peaks" in chromatograms and the normalization of retention times of all the common peaks. ${ }^{24)}$ To standardize the fingerprint, 10 samples from various locations were analyzed with the developed procedure. Peaks existing in all batches of samples were assigned as "common peaks" for CR. Besides, the relative retention time (RRT) and relative peak area (RPA) of each characteristic peak related to the reference peak were calculated for the quantitative parameters of chemical properties in the chromatographic pattern and for similarity analysis of herbs.

More than 20 peaks were observed in the chromatogram of CR extracts, among which 11 peaks (denoted from 1 to 11) were defined as common peaks because they occur in all samples (Fig. 4b). Peaks 4, 7, 10, 11 in the chromatogram were identified to be compounds $\mathbf{1}, \mathbf{2}, \mathbf{3}$ and $\mathbf{4}$, respectively, by compared with the chromatogram of standard solution (Fig. 4a).

Correlation coefficient is used as a measure for similarity analysis. The chromatogram of a standardized extract is rec-
Table 3. The Similarities of Curculigo orchioides Collected from Different Geographic Regions in China

\begin{tabular}{cccc}
\hline \hline Sample $^{a)}$ & Similarities $^{b)}$ & Sample $^{a)}$ & Similarities $^{b)}$ \\
\hline XM-01 & 0.977 & XM-06 & 0.977 \\
XM-02 & 0.890 & XM-07 & 0.923 \\
XM-03 & 0.921 & XM-08 & 0.973 \\
XM-04 & 0.947 & XM-09 & 0.946 \\
XM-05 & 0.970 & XM-10 & 0.912 \\
\hline
\end{tabular}

a) The samples are the same as listed in Table 1.b) Calculation based on the mean chromatogram among ten batches.

ommended to serve as the reference profile, but unfortunately it is rarely available. Therefore, the mean or median chromatographic profile of the data set is usually used. In our work, similarity analysis was performed by comparing between their mean chromatogram and individual chromatogram of each sample via Chromatographic Fingerprint Similarity Evaluation software published by SFDA. As listed in Table 3, the similarity index was in a range of $0.770-0.989$, which suggested that the samples from different habitats shared the similar chromatographic patterns as shown in Fig. 5.

Validation of HPLC-DAD Quantitative Methods Validation of the developed HPLC-DAD method on quantitation of four phenolic compounds was carried out by linearity, precision and accuracy. The regression equations for the four analytes were shown in Table 4 . All the correlation coefficients $\left(r^{2}\right)$ of these calibration curves were higher than 0.999 within the test range. The LOD and LOQ were in the range of $0.58-2.40 \mu \mathrm{g} / \mathrm{mL}$ and $1.65-7.80 \mu \mathrm{g} / \mathrm{mL}$, respectively. Table 5 showed the results of inter and intra precision of the four analytes and their RSD values were less than 3.0\%. Besides, repeatability studies of this method proved that this assay has 
Table 4. Linear Regression Data, LOD and LOQ of the Investigated Compounds $(n=6)$

\begin{tabular}{|c|c|c|c|c|c|c|c|}
\hline No. & Analytes & $\begin{array}{l}\text { Retention time } \\
\quad(\min )\end{array}$ & $\begin{array}{l}\text { Regression } \\
\text { equation }^{a)}\end{array}$ & $r^{2}$ & $\begin{array}{l}\text { Linear range } \\
(\mu \mathrm{g} / \mathrm{mL})\end{array}$ & $\begin{array}{c}\text { LOD } \\
(\mu \mathrm{g} / \mathrm{mL})\end{array}$ & $\begin{array}{c}\text { LOQ } \\
(\mu \mathrm{g} / \mathrm{mL})\end{array}$ \\
\hline 1 & Orcinol glucoside & 11.375 & $y=13.463 x-44.257$ & 0.9991 & $250-5000$ & 1.25 & 5.10 \\
\hline 2 & Orcinol & 18.739 & $y=34.175 x-9.567$ & 0.9990 & $20-400$ & 0.58 & 1.65 \\
\hline 3 & 2,6-Dimethoxybenzoic acid & 25.170 & $y=27.68 x-6.590$ & 0.9994 & $20-400$ & 0.60 & 1.75 \\
\hline 4 & Curculigoside & 30.471 & $y=17.916 x-18.588$ & 0.9993 & $100-2000$ & 2.40 & 7.80 \\
\hline
\end{tabular}

a) $x$ refers to the concentration $(\mu \mathrm{g} / \mathrm{mL}), y$ the peak area, and $r^{2}$ is the correlation coefficient of the equation, LOD, limit of detection, LOQ, limit of quantitation.

Table 5. Results of Precision, Repeatability and Accuracy Studies

\begin{tabular}{|c|c|c|c|c|c|c|c|c|}
\hline \multirow{3}{*}{ Analytes } & \multicolumn{4}{|c|}{ Precision } & \multicolumn{2}{|c|}{ Repeatability $(n=5)$} & \multicolumn{2}{|c|}{ Recovery $^{b)}(n=6)$} \\
\hline & \multicolumn{2}{|c|}{ Intra-day $(n=6)$} & \multicolumn{2}{|c|}{ Inter-day $(n=6)$} & \multirow{2}{*}{ Mean (mg/g) } & \multirow{2}{*}{ RSD (\%) } & \multirow{2}{*}{ Mean (\%) } & \multirow{2}{*}{$\operatorname{RSD}(\%)$} \\
\hline & Mean (mg/L) & $\operatorname{RSD}^{a)}(\%)$ & Mean $(\mathrm{mg} / \mathrm{L})$ & $\operatorname{RSD}^{a)}(\%)$ & & & & \\
\hline 1 & 294.87 & 0.05 & 292.21 & 0.32 & 1.73 & 2.40 & 102.82 & 2.30 \\
\hline 2 & 23.90 & 0.19 & 23.20 & 0.87 & 0.07 & 2.40 & 96.03 & 2.66 \\
\hline 3 & 24.61 & 0.36 & 23.87 & 1.02 & 0.22 & 1.87 & 101.25 & 2.59 \\
\hline 4 & 118.49 & 0.10 & 116.54 & 0.65 & 2.14 & 1.59 & 102.49 & 1.75 \\
\hline
\end{tabular}

a) $\operatorname{RSD}(\%)=($ SD of amount detected $/$ mean of amount detected $) \times 100, b)$ Recovery $(\%)=100 \times($ detected amount - original amount $/$ spiked amount, data was presented as mean of three experiments.

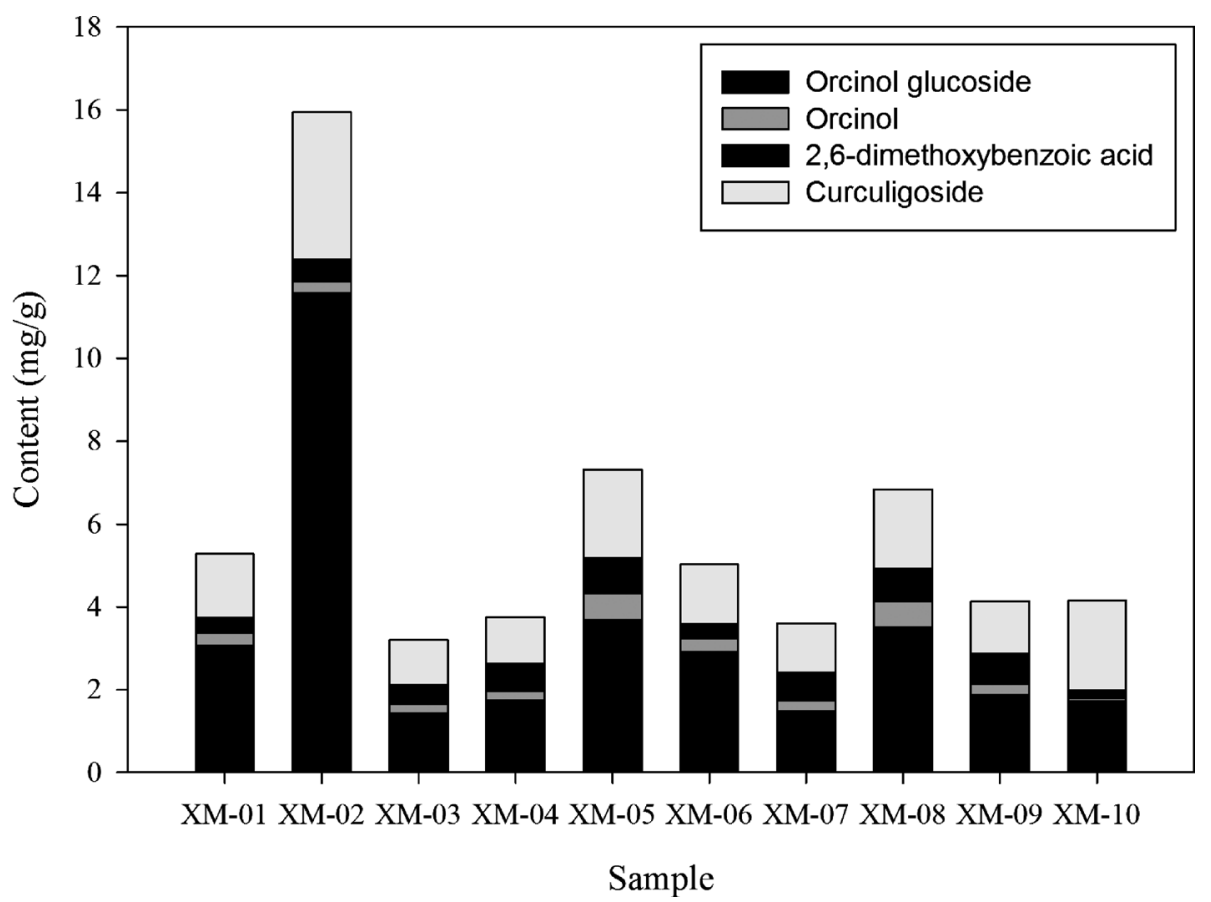

Fig. 6. Contents of 4 Markers in 10 Samples

good reproducibility with RSD less than $5.0 \%(n=5)$ for the four analytes. Recoveries for all four analytes were between 93.2 and $107.5 \%$ and all RSD values were less than $5.0 \%$. Therefore, the above parameters demonstrated that the method is considered to be accurate for simultaneously quantitation of the four phenolic compounds.

Quantitation of Compounds in CR Samples For the simultaneous determination of four phenolic compounds in CR from different production bases, the developed HPLC method was used by comparing the retention times and online UV spectra with those of standards. The amounts of the 4 analytes in the samples were then calculated. As shown in Fig. 6, the results indicate that the content variability is quite significant. The content of orcinol glucoside ranged from 1.43 to $11.58 \mathrm{mg} / \mathrm{g}$ while the content of orcinol ranged from 0.06 to $0.65 \mathrm{mg} / \mathrm{g}$. As for the contents of curculigoside, listed in the latest version of Chinese pharmacopoeia, all samples were passed $(1.74 \pm 0.76 \mathrm{mg} / \mathrm{g})$ and be able to be served as medical use.

\section{Conclusion}

An HPLC-DAD method including simple and accurate quantitation on four phenolic components and fingerprint analysis has been developed to evaluate the quality of CR samples from different geographic areas. This method can assess the quality of this herb more comprehensively while compared 
to previous method which determining on individual component. The results of HPLC fingerprint and quantitation of four phenolic compounds indicated that the samples from different regions shared a similar HPLC chromatographic pattern, and large variations in the contents of phenolic compounds showed among ten different samples. Therefore, the simultaneous determination of all these active components contained in $\mathrm{CR}$ is necessary to improve the quality control level of this medicine.

Acknowledgments This work was supported by the National Natural Science Foundation of China (No. 30873150), and was part of the work of the Hong Kong Chinese Material Madica Standard Project.

\section{References}

1) State Pharmacopoeia Commission of People's Republic of China, "Pharmacopoeia of the People's Republic of China," Vol. 1, China Medical Science and Technology Press, Beijing, China, 2010, p. 94.

2) Soni N., Lal V. K., Agrawal S., Verma H., Adv. Res. Pharm. Biol., 1, 130-138 (2011).

3) Venukumar M. R., Latha M. S., Indian J. Pharmacol., 34, 269-275 (2002).

4) Lakshmi V., Pandey K., Puri A., Saxena R. P., Saxena K. C., J. Ethnopharmacol., 89, 181-184 (2003).

5) Bafna A. R., Mishra S. H., J. Ethnopharmacol., 104, 1-4 (2006).

6) Jiao L., Cao D. P., Qin L. P., Han T., Zhang Q. Y., Zhu Z., Yan F., Phytomedicine, 16, 874-881 (2009).

7) Vijayanarayana K., Rodrigues R. S., Chandrashekhar K. S., Subrahmanyam E. V., Subrahmanyam E. V. S., J. Ethnopharmacol., 114, 241-245 (2007).
8) Madhavan V., Joshi R., Murali A., Yoganarasimhan S. N., Pharm. Biol., 45, 18-21 (2007).

9) Pandit P., Singh A., Bafna A. R., Kadam P. V., Patil M. J., Indian J. Pharm. Sci., 70, 440-444 (2008).

10) Valls J., Richard T., Larronde F., Leblais V., Muller B., Delaunay J. C., Monti J. P., Ramawat K. G., Mérillon J. M., Fitoterapia, 77, 416-419 (2006).

11) Zuo A. X., Shen Y., Jiang Z. Y., Zhang X. M., Zhou J., Lü J., Chen J. J., Fitoterapia, 81, 910-913 (2010).

12) Xu J. P., Xu R. S., Phytochemistry, 31, 2455-2458 (1992).

13) Yokosuka A., Sato K., Mimaki Y., Phytochemistry, 71, 2174-2181 (2010).

14) Zuo A. X., Shen Y., Jiang Z. Y., Zhang X. M., Zhou J., Lü J., Chen J. J., J. Asian Nat. Prod. Res., 14, 407-412 (2012).

15) Wu X. Y., Li J. Z., Guo J. Z., Hou B. Y., Molecules, 17, 10108-10118 (2012).

16) Tian Z., Yu W., Liu H. B., Zhang N., Li X. B., Zhao M. G., Liu S. B., Food Chem. Toxicol., 50, 4010-4015 (2012).

17) Wang Y., Zhao L., Wang Y., Xu J., Nie Y., Guo Y., Tong Y., Qin L., Zhang Q., Acta Biochim. Biophys. Sin. (Shanghai), 44, 431-441 (2012).

18) Pan X., Guo S. H., Chin. Pharm. J., 37, 370-372 (2002).

19) Gong F., Liang Y. Z., Xie P. S., Chau F. T., J. Chromatogr. A, 1002, 25-40 (2003)

20) Kang J., Zhou L., Sun J. H., Han J., Guo D. A., J. Pharm. Biomed. Anal., 47, 778-785 (2008).

21) Chen C. X., Ni W., Mei W. L., Acta Bot. Yunnan, 21, 521-524 (1999).

22) Cao D. P., Han T., Zheng Y. N., Qin L. P., Zhang Q. Y., Acad. J. Second Mil. Med. Univ., 30, 194-197 (2009).

23) Li N., Tan N. H., Zhou J., Acta Bot. Yun., 25, 711-715 (2003).

24) Li J., Li W. Z. M., Huang W., Cheung A. W. H., Bi C. W. C., Duan R., Guo A. J. Y., Dong T. T. X., Tsim K. W. K., J. Chromatogr. A, 1216, 2071-2078 (2009). 